\title{
Analysis of the association between CD40 and CD40 ligand polymorphisms and systemic sclerosis
}

\author{
María Teruel ${ }^{1 *}$, Carmen P Simeon ${ }^{2}$, Jasper Broen ${ }^{3}$, Madelon C Vonk ${ }^{3}$, Patricia Carreira ${ }^{4}$, Maria Teresa Camps ${ }^{5}$, \\ Rosa García-Portales ${ }^{6}$, Esmeralda Delgado-Frías ${ }^{7}$, Maria Gallego ${ }^{8}$, Gerard Espinosa $^{9}$, \\ the Spanish Scleroderma Group ${ }^{10}$, Lorenzo Beretta ${ }^{11}$, Paolo Airó ${ }^{12}$, Claudio Lunardi ${ }^{13}$, Gabriela Riemekasten ${ }^{14}$, \\ Torsten Witte ${ }^{15}$, Thomas Krieg ${ }^{16}$, Alexander Kreuter ${ }^{17}$, Jörg HW Distler ${ }^{18}$, Nicolas Hunzelmann ${ }^{16}$, \\ Bobby P Koeleman ${ }^{19}$, Alexandre E Voskuyl ${ }^{20}$, Annemie J Schuerwegh ${ }^{21}$, Miguel Ángel González-Gay ${ }^{22}$, \\ Timothy RDJ Radstake ${ }^{23}$ and Javier Martin ${ }^{1}$
}

\begin{abstract}
Introduction: The aim of the present study was to investigate the possible role of CD40 and CD40 ligand (CD4OLG) genes in the susceptibility and phenotype expression of systemic sclerosis (SSC).

Methods: In total, 2,670 SSc patients and 3,245 healthy individuals from four European populations (Spain, Germany, The Netherlands, and Italy) were included in the study. Five single-nucleotide polymorphisms (SNPs) of CD40 (rs1883832, rs4810485, rs1535045) and CD40LG (rs3092952, rs3092920) were genotyped by using a predesigned TaqMan allele-discrimination assay technology. Meta-analysis was assessed to determine whether an association exists between the genetic variants and SSC or its main clinical subtypes.
\end{abstract}

Results: No evidence of association between CD40 and CD4OLG genes variants and susceptibility to SSc was observed. Similarly, no significant statistical differences were observed when SSc patients were stratified by the clinical subtypes, the serologic features, and pulmonary fibrosis.

Conclusions: Our results do not suggest an important role of CD40 and CD4OLG gene polymorphisms in the susceptibility to or clinical expression of SSc.

\section{Introduction}

Systemic sclerosis (SSc) is an autoimmune disease of the connective tissue characterized by excessive fibrosis of the dermis and vascular damage. It also affects internal organs, such as the lung, gastrointestinal, and vascular systems [1]. SSc is a complex polygenic disease in which environmental and genetic factors are involved in the susceptibility to this disease. Candidate gene and genome-wide association studies (GWASs) performed in SSc have identified new loci implicated in the susceptibility to SSc [2]. Nevertheless, the complete genetic components of SSc remain unknown.

\footnotetext{
* Correspondence: mteruel@ipb.csic.es

'Instituto de Parasitología y Biomedicina López-Neyra, IPBLN-CSIC, Avda. del Conocimiento s/n. 18010, Granada, SpainArmilla (Granada), Spain Full list of author information is available at the end of the article
}

CD40 is a member of the tumor necrosis factor receptor superfamily (TNFR), and it is expressed on the surface of several immune and nonhematopoietic cells, such as B cells, macrophages, dendritic cells, fibroblasts, and endothelial cells in certain pathogenic conditions [3]. Its ligand, CD40LG (CD154), is expressed mainly on the surface of $\mathrm{CD}^{+} \mathrm{T}$ cells. CD40-CD40LG interactions are necessary for the activation of both humoral and cellular immune responses [3]. The CD40-CD40LG pathway has been suggested to play an important role in the pathogenesis of autoimmune diseases [4]. An increase of soluble CD40LG (sCD40LG) has been observed in many autoimmune diseases, such as systemic lupus erythematosus (SLE) [5], rheumatoid arthritis (RA) [6], and Graves disease (GD) [7]. Interestingly, patients with SSc and limited cutaneous disease have higher levels of 
sCD40LG in the plasma than those of the diffuse cutaneous disease [8]. Similarly, high levels of CD40 protein were observed in both the plasma [9] and the cell surface of skin fibroblasts [10] from SSc patients. In addition, previous studies reported the association of $C D 40$ polymorphisms with susceptibility to a number of autoimmune diseases, such as GD [11], multiple sclerosis [12], RA [13,14], Crohn disease [15], and with visual ischemic manifestations in individuals with biopsy-proven giant cell arteritis [16]. Nevertheless, in the case of SLE, contradictory data exist [17-19]. In addition, mutations of CD4OLG were observed in patients with the hyper-immunoglobulin M (IgM) syndrome [20], and genetic variations located at the $3 \mathrm{UTR}$ of the CD4OLG gene were associated with two autoimmune diseases, SLE [21] and RA [22].

Taking into account these considerations, we aimed to investigate the potential association of CD4O and CD4OLG genes polymorphism with SSc.

\section{Materials and methods Patients}

In total, 2,670 SSc patients and 3,245 healthy individuals from four European populations were included in this study (Spain: cases, 1,103; controls, 1,610; Germany: cases, 554; controls, 437; The Netherlands: cases, 380; controls, 489; Italy: cases, 633; controls, 709). All the patients fulfilled the 1980 American College of Rheumatology (ACR) classification criteria for SSc [23]. Limited cutaneous disease (lcSSc) was defined as definite skin thickening confined to the distal extremities, whereas cases of diffuse cutaneous disease (dcSSc) required also the involvement of skin proximal to the knees and elbow [24,25]. Measurement of main SSc-specific autoantibodies, anti-centromere antibodies (ACAs), and antitopoisomerase I antibodies (ATAs), was performed by using standard methods. Pulmonary fibrosis data were investigated by using a computed tomography scan. The main features of all populations included in this study were previously reported [26-28].

Patients and controls were included in the study after written informed consent, according to the declaration of Helsinki. The study was approved by local ethical committees from all the participating centers.

\section{SNPs selection and genotyping}

DNA from patients and controls was obtained by using standard methods. CD40 is located on chromosome 20q13.12. Three single-nucleotide polymorphisms (SNPs) of CD40 associated with other autoimmune diseases were selected. rs1883832 had been associated with GD [11]; whereas rs4810485, in linkage disequilibrium with rs1883832 $\left(r^{2}=0.95\right)$, has been identified as a new risk factor for RA [13]. Furthermore, rs1535045 has been associated with subclinical atherosclerosis in diabetes families [29]. CD4OLG is found on chromosome Xq26.3. Two genetic variants located in 5 UTR (rs3092952) and 3 UTR (rs3092920) of CD40LG $\left(r^{2}=\right.$ 0.38 ) were selected. These SNPs are located in different haplotype blocks of CD4OLG [17]. The variant rs3092920 is located near the 3 UTR microsatellite, which was previously associated with RA and SLE [21,22]; whereas rs3092952 is a functional variant related to the levels of sCD40LG in plasma [30].

All SNPs were genotyped in the same center by using a TaqMan SNP genotyping assay in a 7900 HT RealTime polymerase chain reaction (PCR) system, by following the conditions recommended by the manufacturer (Applied Biosystems, Foster City, CA, USA). About $10 \%$ of the patients were genotyped twice to verify the genotyping consistency, showing $99 \%$ identical genotypes. The genotyping call-rate success was $>95 \%$ for both cases and controls in all populations.

\section{Statistical analysis}

The Hardy-Weinberg equilibrium (HWE) was tested by means of the Fisher Exact test or $\chi^{2}$ when necessary. The case-control association study was performed by using a $2 \times 2$ contingency table with $\chi^{2}$ to obtain $P$ values, odds ratios (ORs), and $95 \%$ confidence intervals (CIs). Combined OR was calculated according to a fixed-effects model (Mantel-Haenszel meta-analysis), and the heterogeneity of OR among all populations was calculated by using the Breslow-Day test. $P$ values $<0.05$ were considered statistically significant. Statistical analyses were carried out with PLINK [31].

The estimation of the power of the study to detect an effect of a polymorphism in disease susceptibility was performed by using The CaTS Power Calculator software [32].

\section{Results}

\section{CD40 gene variants in SSC}

Three CD40 polymorphisms were genotyped in four European populations. First, we analyzed the cohorts individually and then combined the samples in a pooled analysis. Table 1 describes allelic distribution of the three SNPs in the pooled analysis, and Additional file 1, Table S1-3 contains detailed data for each population. Both cases and controls were confirmed to be in HWE in all populations. No evidence of association between CD40 polymorphisms and susceptibility to SSc was observed in the pooled analysis (allelic $P$ value rs1883832: $P=0.61$; OR, 1.02 ; $95 \% \mathrm{CI}, 0.94$ to 1.11 ; rs4810485: $P=0.42$; OR, $1.04 ; 95 \% \mathrm{CI}, 0.95$ to 1.13 ; rs1535045: $P=0.275$; OR, 0.95 ; $95 \% \mathrm{CI}, 0.88$ to 1.04 ).

To investigate the possible influence of the CD40 polymorphisms with clinical features, we stratified the 
Table 1 Pooled analysis of CD40 polymorphisms

\begin{tabular}{|c|c|c|c|c|c|c|c|}
\hline SNP & Change & Samples set & $N$ & $\begin{array}{l}\text { Minor allele, } \\
\text { no. (frequency) }\end{array}$ & $P$ value & OR $[95 \% \mathrm{Cl}]$ & $P-B D$ \\
\hline \multirow[t]{7}{*}{ rs1883832 } & $\mathrm{T} / \mathrm{C}$ & Controls & 3,138 & $1,427(0.277)$ & & & \\
\hline & & SSC & 2,605 & $1,424(0.274)$ & 0.610 & $1.02[0.94-1.11]$ & 0.904 \\
\hline & & ICSSC & 1,758 & $987(0.276)$ & 0.246 & $1.06[0.96-1.16]$ & 0.496 \\
\hline & & dcSSc & 860 & $451(0.271)$ & 0.683 & $0.97[0.86-1.10]$ & 0.446 \\
\hline & & $\mathrm{ACA}+$ & 1,077 & $592(0.261)$ & 0.879 & 1.01 [0.90-1.13] & 0.355 \\
\hline & & ATA + & 716 & $416(0.293)$ & 0.108 & 1.11 [0.98-1.26] & 0.946 \\
\hline & & Pulmonary fibrosis & 702 & $394(0.278)$ & 0.433 & $1.05[0.92-1.20]$ & 0.802 \\
\hline \multirow[t]{7}{*}{ rs4810485 } & $\mathrm{G} / \mathrm{T}$ & Controls & 3,122 & $1,652(0.272)$ & & & \\
\hline & & $\mathrm{SSC}$ & 2,560 & $1,388(0.274)$ & 0.420 & 1.04 [0.95-1.13] & 0.935 \\
\hline & & ICSSC & 1,736 & $967(0.277)$ & 0.155 & 1.07 [0.97-1.18] & 0.481 \\
\hline & & dcSSc & 839 & $436(0.269)$ & 0.817 & 0.99 [0.87-1.12] & 0.600 \\
\hline & & $\mathrm{ACA}+$ & 1,071 & $580(0.257)$ & 0.844 & 1.01 [0.90-1.13] & 0.399 \\
\hline & & ATA + & 699 & $402(0.292)$ & 0.080 & 1.12 [0.99-1.28] & 0.890 \\
\hline & & Pulmonary fibrosis & 682 & $375(0.272)$ & 0.483 & $1.05[0.92-1.20]$ & 0.605 \\
\hline \multirow[t]{7}{*}{ rs1535045 } & $\mathrm{T} / \mathrm{C}$ & Controls & 3,147 & $1,595(0.247)$ & & & \\
\hline & & SSC & 2,585 & $1,272(0.243)$ & 0.275 & $0.95[0.88-1.04]$ & 0.560 \\
\hline & & ICSSC & 1,749 & $860(0.251)$ & 0.375 & $0.96[0.87-1.05]$ & 0.334 \\
\hline & & dcSSc & 850 & $411(0.228)$ & 0.275 & $0.93[0.82-1.06]$ & 0.746 \\
\hline & & $\mathrm{ACA}+$ & 1,075 & $525(0.241)$ & 0.348 & $0.95[0.84-1.06]$ & 0.844 \\
\hline & & ATA + & 707 & $369(0.264)$ & 0.669 & $1.03[0.90-1.18]$ & 0.640 \\
\hline & & Pulmonary fibrosis & 696 & $340(0.250)$ & 0.396 & $0.94[0.82-1.08]$ & 0.028 \\
\hline
\end{tabular}

Controls are used as reference for all comparisons. All $P$ values have been calculated for the allelic model by using the Mantel-Haenszel test under fixed effect. P_BD, $P$ value by the Breslow-Day method.

patients according to the main SSc manifestations. However, we did not observe evidence of association after comparing lcSSc and dcSSc with healthy subjects (see Table 1). Additionally, we compared the presence of SSc-specific autoantibodies in the patients with the healthy individuals, but no significant differences were observed (Table 1). Likewise, no significant association was observed when patients with pulmonary fibrosis were compared with healthy controls (Table 1).

\section{CD40LG gene variants in SSc}

Because CD4OLG is located on the $\mathrm{X}$-chromosome and shows the sexual bias of this disease, we performed the analysis separately for each gender. Table 2 shows the allelic frequencies in SSc females of the two CD4OLG polymorphisms in the pooled analysis, and Additional file 1, Table S4-5 shows the frequencies for each population. Deviations from HWE were not observed. With the Mantel-Haenzel test, the genotype and allele frequencies were similar between SSc patients and healthy individuals (allelic $P$ value rs3092952: $P=0.44$; OR, 0.96; $95 \%$ CI, 0.85 to 1.07 ; rs3092920: $P=0.565$; OR, 0.96; $95 \% \mathrm{CI}$, 0.83 to 1.11 ). No statistical differences were observed when SSc patients were stratified by common subtype of the disease, the presence of SSc-specific autoantibodies, and pulmonary fibrosis (Table 2).
In addition, we analyzed these two polymorphisms in SSc male patients, but no evidence of association was found in the combined analyses (see Additional file 1, Table S6-7). However, these results should be interpreted with caution because the statistical power is insufficient to detect association because of low sample size.

\section{Discussion}

The important role of the CD40-CD40LG pathway in autoimmunity [4], together with the association of the CD40 gene with a number of autoimmune diseases, prompted us to investigate for the first time the contribution of CD40 and CD4OLG genes in SSc.

Despite the previous findings [8-10], we observed no evidence of association of the CD40 or CD4OLG gene variants analyzed with SSc. It was also the case when SSc patients were stratified by the SSc clinical subtypes, specific autoantibodies, or pulmonary fibrosis. We analyzed a large European population from four different countries to increase the robustness of the study. In this regard, our combined study had an estimated power of $92 \%$ to detect the relative risk, with OR of 1.15 obtained for RA susceptibility [13,14], at the $5 \%$ significance level. Therefore, it seems unlikely that the absence of association found in our study would be due to Type II error. 
Table 2 Pooled analysis of CD40LG polymorphisms in female SSc patients and controls

\begin{tabular}{|c|c|c|c|c|c|c|c|}
\hline SNP & Change & Samples set & $N$ & $\begin{array}{l}\text { Minor allele, } \\
\text { no. (frequency) }\end{array}$ & $P$ value & OR $[95 \% \mathrm{Cl}]$ & $P \_$BD \\
\hline \multirow[t]{7}{*}{ rs3092952 } & $\mathrm{G} / \mathrm{A}$ & Controls & 1,795 & 655 (0.176) & & & \\
\hline & & SSC & 2,082 & 735 (0.186) & 0.440 & $0.96[0.85-1.07]$ & 0.18 \\
\hline & & ICSSC & 1,446 & $515(0.188)$ & 0.592 & $0.97[0.85-1.10]$ & 0.12 \\
\hline & & dcSSc & 635 & $219(0.179)$ & 0.307 & $0.92[0.77-1.09]$ & 0.73 \\
\hline & & $\mathrm{ACA}+$ & 924 & $338(0.195)$ & 0.978 & $1.00[0.87-1.16]$ & 0.06 \\
\hline & & ATA + & 533 & $184(0.188)$ & 0.375 & $0.92[0.77-1.11]$ & 0.50 \\
\hline & & Pulmonary fibrosis & 542 & $198(0.173)$ & 0.735 & $0.97[0.81-1.16]$ & 0.41 \\
\hline \multirow[t]{7}{*}{ rs3092920 } & $T / G$ & Controls & 1,789 & $376(0.107)$ & & & \\
\hline & & SSC & 2,104 & $426(0.105)$ & 0.565 & $0.96[0.83-1.11]$ & 0.89 \\
\hline & & ICSSC & 1,456 & $310(0.112)$ & 0.929 & $1.01[0.86-1.18]$ & 0.97 \\
\hline & & deSSc & 647 & $116(0.091)$ & 0.120 & $0.84[0.67-1.05]$ & 0.36 \\
\hline & & $\mathrm{ACA}+$ & 939 & $201(0.111)$ & 0.924 & $1.01[0.84-1.21]$ & 0.48 \\
\hline & & ATA + & 541 & $106(0.103)$ & 0.434 & $0.91[0.73-1.15]$ & 0.86 \\
\hline & & Pulmonary fibrosis & 549 & $124(0.106)$ & 0.657 & $1.05[0.84-1.31]$ & 0.55 \\
\hline
\end{tabular}

Controls are used as reference for all comparisons. All $P$ values have been calculated for the allelic model by using the Mantel-Haenszel test under fixed effect. $P \_B D, P$ value by the Breslow-Day method.

In the present study, we analyzed the functional $C D 40$ $1 \mathrm{C} / \mathrm{T}$ polymorphism (rs1883832). This genetic variant is located at -1 from the ATG, within a Kozak sequence, a stretch of nucleotides essential for translation that flanks the start codon in vertebrate genes [33]. The presence of a major allele $(C)$ in this SNP is associated with the increase of the efficiency of CD40 translations [11]. Although quantitative differences between CD40 mRNA and proteins have been observed in SSc skin fibroblasts [10], the absence of association found for rs 1883832 suggests that this variant might not affect the translation of $C D 40$ mRNA. This process may be upregulated in these abnormal skin fibroblasts, or other genes of the CD40 signaling pathway may influence the $C D 40$ expression. However, functional studies in this way should be constructed before excluding an association between this variant and the CD40 expression in SSc.

Although $C D 40$ might be a common susceptibility locus for some autoimmune diseases [11-16], our results do not suggest an important role of $C D 40$ in the susceptibility to SSc. Several genes have been recently disclosed to play a function in the susceptibility to autoimmune diseases, suggesting that these diseases share a genetic background [34]. However, these loci may not be universal genetic factors for autoimmune disorders; therefore, the autoimmunity might result from specific and multiple pleiotropic effects [19]. Also, other genes are unique for each disease, reflecting a specific etiology $[19,34]$. Additional studies are required for the identification of specific and shared genetic pathways that contribute to a better understanding of the pathogenesis of the autoimmune diseases.

The role of the CD4OLG in the susceptibility to autoimmune diseases has not been investigated as broadly as that of $C D 40$, mainly because this gene is located on the $x$ chromosome. The different prevalences of these diseases in both genders can suggest that genes located on the $\times$ chromosome could be susceptibility factors in autoimmune diseases; however, few studies analyzed polymorphisms on this chromosome. Mutations on this gene are associated with X-linked hyper-IgM syndrome, a familial genetic disorder characterized by an increase of IgM level and a decrease of IgG and IgA [20], but in SLE, no evidence of association has been found [17]. Similarly, our results show that the CD4OLG gene may not be SSc susceptibility loci.

\section{Conclusions}

Our results do not suggest an important role of $C D 40$ and CD4OLG genes in the susceptibility to SSc. Additional studies are required to draw firm conclusions about the exact role of the CD4O and CD4OLG genes in SSc susceptibility because other variants might be involved in SSc. Future studies involving other genes of the CD40-CD40LG pathway should be conducted to elucidate fully the contribution of this pathway in the pathogenesis of SSc.

\section{Additional material}

Additional file 1: Supplementary Tables 1 through 7. Genotype and allele distribution of the CD40 and CD4OLG polymorphisms for each population included in the current study.

\section{Abbreviations}

ACA: anti-centromere antibody; ATA: anti-topoisomerase I antibody; Cl: confidence interval; dcSSc: diffuse cutaneous subtype; GD: Graves disease; 
GWAS: genome-wide association study; HWE: Hardy-Weinberg equilibrium; ICSSc: limited cutaneous subtype; OR: odds ratio; P-BD: $P$ value by BreslowDay method; RA: rheumatoid arthritis; SLE: systemic lupus erythematosus; SNP: single-nucleotide polymorphism; SSc: systemic sclerosis.

\section{Acknowledgements}

We thank Sofia Vargas, Sonia Garcia, and Gema Robledo for their excellent technical assistance, and all the patients and healthy controls for kindly accepting their essential collaboration. We thank Banco Nacional de ADN (University of Salamanca, Spain) for supplying part of the control material. We also thank EUSTAR (The EULAR Scleroderma Trials and Research Group) and the German Network of Systemic Sclerosis for the facilitation of this project.

This work was supported by the following grants. JM was funded by SAF2009-11110 from the Spanish Ministry of Science, by CTS-4977 and PI0590-2010 from Junta de Andalucía, and by RETICS Program, RD08/0075 (RIER) from Instituto de Salud Carlos III (ISCIII), within the VI PN de I+D+i 2008-2011 (FEDER). T.R.D.J.R. was funded by the VIDI laureate from the Dutch Association of Research (NWO) and Dutch Arthritis Foundation (National Reumafonds). JM and TRDJR were sponsored by the Orphan Disease Program grant from the European League Against Rheumatism (EULAR). TW was awarded grants by DFG WI 1031/6.1 and DFG KFO 250 TP03. MT was supported by Spanish Ministry of Science through the program Juan de la Cierva (JCl-2010-08227).

Spanish Scleroderma Group:

Norberto Ortego-Centeno, José Luis Callejas, and Raquel Ríos, Systemic Autoimmune Diseases Unit, Department of Internal Medicine, Hospital Clínico Universitario San Cecilio, Granada; Nuria Navarrete and Antonio Garcia, Department of Internal Medicine, Hospital Virgen de las Nieves, Granada; Antonio Fernández-Nebro, Department of Rheumatology, Hospital Carlos Haya, Málaga; María F. González-Escribano, Department of Immunology, Hospital Virgen del Rocío, Sevilla; Julio Sánchez-Román and Ma Jesús Castillo, Department of Internal Medicine, Hospital Virgen del Rocío, Sevilla; Ma Ángeles Aguirre and Inmaculada Gómez-Gracia, Department of Rheumatology, Hospital Reina Sofía, Córdoba; Benjamín Fernández-Gutiérrez and Luis Rodríguez-Rodríguez, Department of Rheumatology, Hospital Clínico San Carlos, Madrid; Esther Vicente, Department of Rheumatology, Hospital La Princesa, Madrid; Mónica Fernández Castro and José Luis Andreu, Department of Rheumatology, Hospital Puerta del Hierro, Madrid; Paloma García de la Peña, Department of Rheumatology, Hospital Universitario Madrid Norte Sanchinarro, Madrid; Francisco Javier López-Longo and Lina Martínez-Estupiñán, Department of Rheumatology, Hospital General Universitario Gregorio Marañón, Madrid; Anna Pros, Department of Rheumatology, Hospital Del Mar, 08003 Barcelona; Vicente Fonollosa, Department of Internal Medicine, Hospital Valle de Hebrón, Barcelona; Carlos Tolosa, Department of Internal Medicine, Hospital Parc Tauli, Sabadell; Mónica Rodríguez Carballeira, Department of Internal Medicine, Hospital Universitari Mútua Terrasa, Barcelona; Ivan Castellví, Unidad de Reumatología, Department of Internal Medicine, Hospital de la Santa Creu i Sant Pau, Barcelona; Francisco Javier Narváez, Department of Rheumatology, Hospital Universitari de Bellvitge, Barcelona; Francisco Javier Blanco-García, Natividad Oreiro, and María Ángeles Robles, Department of Rheumatology, INIBICHospital Universitario A Coruña, A Coruña; María Victoria Egurbide, Department of Internal Medicine, Hospital de Cruces, Vizcaya; Luis SáezComet, Systemic Autoimmune Diseases Unit, Department of Internal Medicine, Hospital Universitario Miguel Servet, Zaragoza; Ricardo Blanco, Department of Rheumatology, Hospital Universitario Marqués de Valdecilla, Santander; Bernardino Díaz and Luis Trapiella, Department of Internal Medicine, Hospital Central de Asturias, Oviedo; Federico Díaz and Vanesa Hernández, Department of Rheumatology, Hospital Universitario de Canarias, Tenerife; Emma Beltrán, Department of Rheumatology, Hospital del Doctor Peset Aleixandre, Valencia; and José Andrés Román-Ivorra, Department of Rheumatology, Hospital Universitari i Politecnic La Fe, Valencia.

\section{Author details}

1'Instituto de Parasitología y Biomedicina López-Neyra, IPBLN-CSIC, Avda. del Conocimiento s/n. 18010, Granada, SpainArmilla (Granada), Spain. ${ }^{2}$ Department of Internal Medicine, Hospital Valle de Hebron, Passeig de la Vall d'Hebron 11908035 Barcelona, Spain. ${ }^{3}$ Department of Rheumatology, Radboud University Nijmegen Medical Centre, Comeniuslaan 46525 HP Nijmegen, The Netherlands. ${ }^{4}$ Department of Rheumatology, Hospital 12 de
Octubre, Avda. de Córdoba s/n 28041, Madrid, Spain. ${ }^{5}$ Department of Internal Medicine, Hospital Carlos Haya, Avda Carlos Haya s/n 29010 Málaga, Spain. ${ }^{6}$ Department of Rheumatology, Hospital Virgen de la Victoria, Campus de Teatinos s/n 29010 Málaga, Spain. 'Department of Rheumatology, Hospital Universitario de Canarias, Ctra. Cuesta-Taco, s/n 38320, La Cuesta, San Cristóbal de La Laguna, Tenerife, Canarias, Spain. ${ }^{8}$ Department of Internal Medicine, Hospital Central de Asturias, Celestino Villamil, s/n 33006 Oviedo, Spain. ${ }^{9}$ Department of Autoimmune Diseases, Hospital Clinic, Carrer de Villarroel, 17008036 Barcelona, Spain. ${ }^{10}$ See Acknowledgements.

${ }^{11}$ Referral Center for Systemic Autoimmune Diseases, Fondazione IRCCS Ca' Granda Ospedale Maggiore Policlinico Via Francesco Sforza, 3520122 and University of Milan, Via Festa del Perdono, 7 20122, Milan, Italy.

${ }^{12}$ Rheumatology Unit and Chair, Spedali Civili, Università degli Studi, Piazzale Spedali Civili, 125123 Brescia, Italy. ${ }^{13}$ Department of Medicine, Policlinico GB Rossi, Università degli studi di Verona, Via dell'Artigliere, 837129 Verona, Italy. ${ }^{14}$ Department of Rheumatology and Clinical Immunology, Charité University Hospital and German Rheumatism Research Centre, a Leibniz Institute, Charitéplatz 1, 10117 Berlin, Germany. ${ }^{15}$ Clinic for Immunology and Rheumatology Medical School, Carl-Neuberg-Str, 1 30625, Hannover, Germany. ${ }^{10}$ Department of Dermatology, University of Cologne, Kerpener Str 62, 50924 Köln, Germany. ${ }^{17}$ Department of Dermatology, Allergology, and Venereology, Ruhr University of Bochum, Stiepeler Straße 12944801 Bochum, Germany. ${ }^{18}$ Department of Internal Medicine 3, Institute for Clinical Immunology, University of Erlangen-Nuremberg, Schillerstraße 191054 , Erlangen, Germany. ${ }^{19}$ Section Complex Genetics, Department of Medical Genetics, University Medical Center Utrecht, Universiteitsweg Stratenum 3508 $A B$, Utrecht, The Netherlands. ${ }^{20}$ Department of Rheumatology, VU University Medical Center, De Boelelaan 11171081 HZ Amsterdam, The Netherlands. ${ }^{21}$ Department of Rheumatology, Leiden University Medical Center, Albinusdreef 22300 RC, Leiden, The Netherlands. ${ }^{22}$ Department of Rheumatology, Hospital Universitario Marques de Valdecilla, IFIMAV, Avda. Valdecilla, 25, 39008 Santander, Spain. ${ }^{23}$ Department of Rheumatology and Clinical Immunology, University Utrecht Medical Center, Universiteitsweg 100 Stratenum 3508 AB, Utrecht, The Netherlands.

\section{Authors' contributions}

MT and JM made substantial contributions to conception, design of study, and interpretation of data. MT carried out genotyping, analysis of data, and drafted the manuscript. CPS, JB, MCV, PC, MTC, RGP, EDF, MG, GE, LB, PA, CL, GR, TW, TK, AK, JHWD, NH, BPK, AEV, AJ, AJS, MAGG, TRDJR, and SSG had been involved in the acquisition of clinical data of the patients included in this study as well as the interpretation of the data. JM has been involved in revising of the final manuscript. All authors gave final approval of the version to be published.

\section{Competing interests}

The authors declare that they have no competing interests.

Received: 16 March 2012 Revised: 23 May 2012

Accepted: 25 June 2012 Published: 25 June 2012

\section{References}

1. Gabrielli A, Avvedimento EV, Krieg T: Scleroderma. N Engl J Med 2009, 360:1989-2003.

2. Martin JE, Bossini-Castillo L, Martin J: Unraveling the genetic component of systemic sclerosis. Hum Genet 2012, 131:1023-1037.

3. Elgueta R, Benson MJ, de Vries VC, Wasiuk A, Guo Y, Noelle RJ: Molecular mechanism and function of CD40/CD40L engagement in the immune system. Immunol Rev 2009, 229:152-172.

4. Peters AL, Stunz LL, Bishop GA: CD40 and autoimmunity: the dark side of a great activator. Semin Immunol 2009, 21:293-300.

5. Vakkalanka RK, Woo C, Kirou KA, Koshy M, Berger D, Crow MK: Elevated levels and functional capacity of soluble CD40 ligand in systemic lupus erythematosus sera. Arthritis Rheum 1999, 42:871-881.

6. Tamura N, Kobayashi S, Kato K, Bando H, Haruta K, Oyanagi M, Kuriyama M, Kipps TJ, Hashimoto H: Soluble CD154 in rheumatoid arthritis: elevated plasma levels in cases with vasculitis. J Rheumatol 2001, 28:2583-2590.

7. Faure GC, Bensoussan-Lejzerowicz D, Bene MC, Aubert V, Leclere J: Coexpression of CD40 and class II antigen HLA-DR in Graves' disease thyroid epithelial cells. Clin Immunol Immunopathol 1997, 84:212-215. 
8. Allanore Y, Borderie D, Meune C, Lemarechal H, Weber S, Ekindjian OG, Kahan A: Increased plasma soluble CD40 ligand concentrations in systemic sclerosis and association with pulmonary arterial hypertension and digital ulcers. Ann Rheum Dis 2005, 64:481-483.

9. Komura K, Fujimoto M, Matsushita T, Yanaba K, Kodera M, Kawasuji A, Hasegawa M, Takehara K, Sato S: Increased serum soluble CD40 levels in patients with systemic sclerosis. J Rheumatol 2007, 34:353-358.

10. Fukasawa C, Kawaguchi Y, Harigai M, Sugiura T, Takagi K, Kawamoto M, Hara M, Kamatani N: Increased CD40 expression in skin fibroblasts from patients with systemic sclerosis (SSc): role of CD40-CD154 in the phenotype of SSc fibroblasts. Eur J Immunol 2003, 33:2792-2800.

11. Jacobson EM, Concepcion E, Oashi T, Tomer Y: A Graves' diseaseassociated Kozak sequence single-nucleotide polymorphism enhances the efficiency of CD40 gene translation: a case for translational pathophysiology. Endocrinology 2005, 146:2684-2691.

12. ANZgene: Genome-wide association study identifies new multiple sclerosis susceptibility loci on chromosomes 12 and 20. Nat Genet 2009, 41:824-828.

13. Raychaudhuri S, Remmers EF, Lee AT, Hackett R, Guiducci C, Burtt NP, Gianniny L, Korman BD, Padyukov L, Kurreeman FA, Chang M, Catanese JJ, Ding B, Wong S, van der Helm-van Mil AH, Neale BM, Coblyn J, Cui J, Tak PP, Wolbink GJ, Crusius JB, van der Horst-Bruinsma IE, Criswell LA, Amos Cl, Seldin MF, Kastner DL, Ardlie KG, Alfredsson L, Costenbader KH, Altshuler $D$, et al: Common variants at CD40 and other loci confer risk of rheumatoid arthritis. Nat Genet 2008, 40:1216-1223.

14. Orozco G, Eyre $S$, Hinks A, Ke X, Wellcome Trust Case Control consortium YEAR Consortium, Wilson AG, Bax DE, Morgan AW, Emery P, Steer S, Hocking L, Reid DM, Wordsworth P, Harrison P, Thomson W, Barton A, Worthington J: Association of CD40 with rheumatoid arthritis confirmed in a large UK case-control study. Ann Rheum Dis 2009, 69:813-816.

15. Blanco-Kelly F, Matesanz F, Alcina A, Teruel M, Díaz-Gallo LM, GómezGarcía M, López-Nevot MA, Rodrigo L, Nieto A, Cardeña C, Alcain G, DíazRubio M, de la Concha EG, Fernandez O, Arroyo R, Martín J, Urcelay E: CD40: novel association with crohn's disease and replication in multiple sclerosis susceptibility. PLoS One 2010, 5:e11520.

16. Rodríguez-Rodríguez L, Castañeda S, Vázquez-Rodríguez TR, Morado IC, Marí-Alfonso B, Gómez-Vaquero C, Miranda-Filloy JA, Narvaez J, OrtegoCenteno N, Blanco R, Fernández-Gutiérrez B, Martín J, González-Gay MA: Influence of CD40 rs1883832 polymorphism in susceptibility to and clinical manifestations of biopsy-proven giant cell arteritis. J Rheumatol 2010, 37:2076-2080.

17. Chadha S, Miller K, Farwell L, Lightstone LB, Daly MJ, Rioux JD, Vyse TJ: Haplotype structure of TNFRSF5-TNFSF5 (CD40-CD40L) and association analysis in systemic lupus erythematosus. Eur J Hum Genet 2005, 13:669-676.

18. Vazgiourakis VM, Zervou Ml, Choulaki C, Bertsias G, Melissourgaki M, Yilmaz N, Sidiropoulos P, Plant D, Trouw LA, Toes RE, Kardassis D, Yavuz S, Boumpas DT, Goulielmos GN: A common SNP in the CD40 region is associated with systemic lupus erythematosus and correlates with altered CD40 expression: implications for the pathogenesis. Ann Rheum Dis 2011, 70:2184-2190

19. Ramos PS, Criswell LA, Moser KL, Comeau ME, Williams AH, Pajewski NM, Chung SA, Graham RR, Zidovetzki R, Kelly JA, Kaufman KM, Jacob CO, Vyse TJ, Tsao BP, Kimberly RP, Gaffney PM, Alarcón-Riquelme ME, Harley JB, Langefeld CD, International Consortium on the Genetics of Systemic Erythematosus: A comprehensive analysis of shared loci between systemic lupus erythematosus (SLE) and sixteen autoimmune diseases reveals limited genetic overlap. PLOS Genet 2011, 7:e1002406.

20. Lougaris V, Badolato R, Ferrari S, Plebani A: Hyper immunoglobulin M syndrome due to CD40 deficiency: clinical, molecular, and immunological features. Immunol Rev 2005, 203:48-66.

21. Martin-Donaire T, Losada-Fernandez I, Perez-Chacon G, Rua-Figueroa I, Erausquin C, Naranjo-Hernandez A, Rosado S, Sanchez F, Garcia-Saavedra A, Citores MJ, Vargas JA, Perez-Aciego P: Association of the microsatellite in the $3^{\prime}$ untranslated region of the CD154 gene with rheumatoid arthritis in females from a Spanish cohort: a case-control study. Arthritis Res Ther 2007, 9:R89.

22. Citores MJ, Rua-Figueroa I, Rodriguez-Gallego C, Durantez A, GarciaLaorden MI, Rodriguez-Lozano C, Rodriguez-Perez JC, Vargas JA, PerezAciego P: The dinucleotide repeat polymorphism in the $3^{\prime} U T R$ of the CD154 gene has a functional role on protein expression and is associated with systemic lupus erythematosus. Ann Rheum Dis 2004, 63:310-317.

23. Subcommittee for scleroderma criteria of the American Rheumatism Association Diagnostic and Therapeutic Criteria Committee: Preliminary criteria for the classification of systemic sclerosis (scleroderma). Arthritis Rheum 1980, 23:581-590.

24. LeRoy EC, Black C, Fleischmajer R, Jablonska S, Krieg T, Medsger TA Jr, Rowell N, Wollheim F: Scleroderma (systemic sclerosis): classification, subsets and pathogenesis. J Rheumatol 1988, 15:202-205.

25. LeRoy EC, Medsger TA Jr: Criteria for the classification of early systemic sclerosis. J Rheumatol 2001, 28:1573-1576.

26. Radstake TR, Gorlova O, Rueda B, Martin JE, Alizadeh BZ, PalominoMorales R, Coenen MJ, Vonk MC, Voskuyl AE, Schuerwegh AJ, Broen JC, van Riel PL, van 't Slot R, Italiaander A, Ophoff RA, Riemekasten G, Hunzelmann N, Simeon CP, Ortego-Centeno N, González-Gay MA, González-Escribano MF, Spanish Scleroderma Group, Airo P, van Laar J, Herrick A, Worthington J, Hesselstrand R, Smith V, de Keyser F, Houssiau F, et al: Genome-wide association study of systemic sclerosis identifies CD247 as a new susceptibility locus. Nat Genet 2010, 42:426-429.

27. Gorlova O, Martin JE, Rueda B, Koeleman BP, Ying J, Teruel M, DiazGallo LM, Broen JC, Vonk MC, Simeon CP, Alizadeh BZ, Coenen MJ, Voskuyl AE, Schuerwegh AJ, van Riel PL, Vanthuyne M, van 't Slot R, Italiaander A, Ophoff RA, Hunzelmann N, Fonollosa V, Ortego-Centeno N, González-Gay MA, García-Hernández FJ, González-Escribano MF, Airo P, van Laar J, Worthington J, Hesselstrand R, Smith V, et al: Identification of novel genetic markers associated with clinical phenotypes of systemic sclerosis through a genome-wide association strategy. PLoS Genet 2011, 7:e1002178.

28. Bossini-Castillo L, Martin JE, Broen J, Gorlova O, Simeón CP, Beretta L, Vonk MC, Callejas JL, Castellví I, Carreira P, García-Hernández FJ, Fernández Castro M, Spanish Scleroderma Group, Coenen MJ, Riemekasten G, Witte T, Hunzelmann N, Kreuter A, Distler JH, Koeleman BP, Voskuyl AE, Schuerwegh AJ, Palm Ø, Hesselstrand R, Nordin A, Airó P, Lunardi C, Scorza R, Shiels P, van Laar JM, et al: A GWAS follow-up study reveals the association of the IL12RB2 gene with systemic sclerosis in Caucasian populations. Hum Mol Genet 2012, 21:926-933.

29. Burdon KP, Langefeld CD, Beck SR, Wagenknecht LE, Carr JJ, Rich SS, Freedman Bl, Herrington D, Bowden DW: Variants of the CD40 gene but not of the CD40L gene are associated with coronary artery calcification in the Diabetes Heart Study (DHS). Am Heart J 2006, 151:706-711.

30. Malarstig $A$, Lindahl $B$, Wallentin $L$, Siegbahn A: Soluble CD40L levels are regulated by the $-3459 \mathrm{~A}>\mathrm{G}$ polymorphism and predict myocardial infarction and the efficacy of antithrombotic treatment in non-ST elevation acute coronary syndrome. Arterioscler Thromb Vasc Biol 2006, 26:1667-1673.

31. Purcell $S$, Neale $B$, Todd-Brown $K$, Thomas $L$, Ferreira MA, Bender D, Maller J, Sklar P, de Bakker PI, Daly MJ, Sham PC: PLINK: a tool set for wholegenome association and population-based linkage analyses. Am J Hum Genet 2007, 81:559-575[http://pngu.mgh.harvard.edu/ purcell/plink/].

32. Skol AD, Scott $L$, Abecasis GR, Boehnke M: Joint analysis is more efficient than replication-based analysis for two-stage genome-wide association studies. Nat Genet 2006, 38:209-213[http://www.sph.umich.edu/csg/ abecasis/CaTS/.

33. Kozak M: An analysis of $5^{\prime}$-noncoding sequences from 699 vertebrate messenger RNAs. Nucleic Acids Res 1987, 15:8125-8148.

34. Cho JH, Gregersen PK: Genomics and the multifactorial nature of human autoimmune disease. N Engl J Med 2011, 365:1612-1623.

doi:10.1186/ar3890

Cite this article as: Teruel et al: Analysis of the association between CD40 and CD40 ligand polymorphisms and systemic sclerosis. Arthritis Research \& Therapy 2012 14:R154. 